\title{
ATMOSFERAS MODIFICADAS PARA CONSERVAÇÃO DE CARNES FRESCAS: tendências e aplicabilidade tecnológica do monóxido de carbono
}

\author{
Modified atmosphere packaging for fresh meat: trends and technological \\ application of carbon monoxide
}

\author{
Renata Ernlund Freitas de Macedo ${ }^{[a]}$, Luciane Silvia Rossa ${ }^{[b]}$, \\ Laura Cezar de Andrade Staut Nunes ${ }^{[c]}$, Raquel Szygalski Biasi ${ }^{[b]}$, Cristiano Gomes ${ }^{[b]}$, \\ Luciana do Amaral Gurgel Galeb ${ }^{[b]}$, Peter Gaberz Kirschnik ${ }^{[\mathrm{d}]}$
}

[a] Médica Veterinária, Doutora em Tecnologia de Alimentos, Professora do Programa de Pós-Graduação em Ciência Animal da Pontifícia Universidade Católica do Paraná (PUCPR), Curitiba, PR - Brasil, e-mail: renata.macedo@pucpr.br

${ }^{[b]}$ Médicos Veterinários, Mestrandos do Programa de Pós-Graduação em Ciência Animal da Pontifícia Universidade Católica do Paraná (PUCPR), Curitiba, PR - Brasil, e-mail: luciane.rossa@pucpr.brquel_biasi@yahoo.com.br, gomescg@yahoo.com.br, lucianagaleb@hotmail.com

${ }^{[c]}$ Zootecnista, aluna ouvinte do Programa de Pós-Graduação em Ciência Animal da Pontifícia Universidade Católica do Paraná (PUCPR), Curitiba, PR - Brasil, e-mail: laurastaut@hotmail.com

[d] Zootecnista, Doutor em Aquicultura, professor do Programa de Pós-Graduação em Ciência Animal da Pontifícia Universidade Católica do Paraná (PUCPR), Curitiba,PR - Brasil, e-mail: peter.k@pucpr.br

\begin{abstract}
Resumo
Atmosfera modificada (AM) consiste na remoção e/ou substituição da atmosfera ao redor do alimento antes de embalá-lo em material impermeável ao vapor d'água e outros gases. O emprego de atmosferas modificadas é bastante difundido comercialmente em carnes frescas, pelo aumento de sua vida de prateleira, bem como pela manutenção da estabilidade microbiológica e sensorial durante a estocagem. No Brasil, o tipo de atmosfera modificada mais empregado para a conservação de carnes frescas é o sistema a vácuo. Apesar de sua eficiência na conservação microbiana da carne e de seu custo acessível, o envase a vácuo não torna a carne atrativa ao consumidor, em função de sua coloração mais escura e aspecto de menos frescor. A cor vermelha brilhante em carnes, que lhe confere aparểncia de frescor, pode ser obtida em atmosferas ricas em oxigênio, bem como em atmosferas com baixas concentrações de monóxido de carbono. Contudo, atmosferas com alto teor de oxigênio podem acelerar processos oxidativos, resultando em alterações no sabor e aroma das carnes. O emprego de monóxido de carbono, apesar de promissor para a conservação de carnes, tem sido questionado em alguns países, devido à sua toxicidade. Tendo em vista a importância comercial dos sistemas de atmosfera modificada para a conservação de carnes, essa revisão aborda os principais tipos de atmosferas e gases utilizados, dando enfoque na aplicabilidade tecnológica do monóxido de carbono em sistemas de embalagens de carnes frescas.
\end{abstract}

Palavras-chave: Embalagem. Carne. Mistura de gases. Cor. Deterioração microbiana.

Rev. Acad., Ciênc. Agrár. Ambient., Curitiba, v. 7, n. 4, p. 469-482, out./dez. 2009 


\begin{abstract}
Modified atmosphere packaging (MAP) is the removal and/or replacement of the atmosphere surrounding the product before sealing in vapor-barrier materials. Modified atmosphere packaging systems are widely applied in fresh meat due to the improvement in shelf life and maintenance of sensory and microbiological stability of meat during storage. The vacuum packaging is the most popular MAP system for fresh meat in Brazil. Despite its efficiency in microbial spoilage control and low cost, it confers dark color to meat, which is related by the consumers with non fresh meat. The bright red color in meat is obtained by the use of high-oxygen packaging or low-oxygen packaging with carbon monoxide (CO). However, high-oxygen atmosphere accelerates oxidative processes in meat, resulting in lipid oxidation and off-flavor development. Although the application of CO in low-oxygen packaging is promising, the utilization of $\mathrm{CO}$ in fresh meat has been controversial in many countries due to its toxicity. Regarding the commercial importance of modified atmosphere for the preservation of fresh meat, this paper presents the different gases and methods of modified atmosphere packaging applied in fresh meat, focusing on the technological application of carbon monoxide.
\end{abstract}

Keywords: Packaging. Meat. Gas mixture. Color. Microbial spoilage

\title{
INTRODUÇÃO
}

Qualidade da carne é um termo formado por uma série de atributos, como cor, aroma, textura e aspecto geral. Esses atributos da carne são afetados tanto por condições de manejo dos animais no pré-abate, quanto por processos bioquímicos e enzimáticos que ocorrem durante a estocagem (ZAKRYS et al., 2009).

A decisão do consumidor para a aquisição de carne bovina fresca é determinada pela percepção de frescor e pela segurança transmitida pelo produto, atribuídas a uma série de características, como cor, aparência, exsudação e aroma. Entre esses atributos, a cor da carne é o principal parâmetro utilizado pelos consumidores para a medida do frescor e decisão de compra. Invariavelmente, os consumidores desejam encontrar na carne bovina fresca pré-embalada uma coloração vermelho brilhante (VENTURINI, 2003; JOHN et al., 2005; LAUZURICA et al., 2005; DE SANTOS et al., 2007).

Uma vez que a coloração é o principal critério em que o consumidor se baseia no momento da compra de carne bovina, é essencial que a estabilidade da cor vermelha brilhante seja mantida durante todo o processo de distribuição, estocagem e comercialização (BARACAT, 2006). Nesse sentido, é de fundamental importância para a manutenção da atratividade e o desejo de compra pelos consumidores o uso de embalagens que preservem a cor da carne, evitem contaminações, reduzam a perda de peso, permitam alguma atividade enzimática para aumentar a maciez e retardem reações de oxidação e deterioração (ZAKRYS et al., 2009).

A embalagem em atmosfera modificada (AM) é um dos métodos utilizados para prolongar a vida útil das carnes. Esse sistema de embalagem influencia o comportamento da carne, por alterar o ambiente interno da embalagem, também conhecido como microambiente. O sistema também reduz a contaminação da carne, além de constituir barreira efetiva ao vapor de água, prevenindo sua perda por evaporação. Porém, a principal característica da alteração da atmosfera gasosa está em sua influência sobre a cor da carne e em determinar a extensão e o tipo de deterioração microbiológica durante sua estocagem (NISHI; FARIA, 2006).

Nos sistemas de embalagem em AM utiliza-se uma mistura de gases que normalmente inclui dióxido de carbono $\left(\mathrm{CO}_{2}\right)$, oxigênio $\left(\mathrm{O}_{2}\right)$ e nitrogênio $\left(\mathrm{N}_{2}\right)$. O sistema de embalagem a vácuo é considerado por muitos autores como um dos sistemas de AM mais empregados para embalagens de

Rev. Acad., Ciênc. Agrár. Ambient., Curitiba, v. 7, n. 4, p. 469-482, out./dez. 2009 
carnes no Brasil. Porém, esse sistema não possibilita a manutenção da coloração vermelho brilhante, o que torna a carne menos atrativa para os consumidores. Por outro lado, as embalagens de carnes compostas por misturas de $\mathrm{CO}_{2}, \mathrm{O}_{2}$ e $\mathrm{N}_{2}$ podem causar descoloração superficial das carnes e acelerar processos oxidativos (LINARES et al., 2008).

No sentido de reduzir os problemas causados por essas misturas de gases, o uso de monóxido de carbono $(\mathrm{CO})$ tem sido proposto em embalagens de carne fresca. Sua principal vantagem nesses sistemas é a manutenção da cor vermelho brilhante nas carnes. Além disso, seu uso evita processos oxidativos e retarda a deterioração microbiana, o que comumente ocorre em sistemas com alto teor de $\mathrm{O}_{2}$ Porém, devido ao potencial efeito tóxico do CO, sua utilização gera controvérsias em alguns países (CORNFORTH; HUNT, 2008).

Tendo em vista os benefícios do uso de atmosferas modificadas em embalagens de carnes frescas sobre a atratividade e a vida útil desses produtos, o presente artigo aborda a ação dos principais tipos de atmosferas e gases utilizados em embalagens para carnes, com foco na aplicabilidade de uso do CO.

\section{DEFINIÇÃO DE ATMOSFERA MODIFICADA (AM)}

O termo AM se refere ao acondicionamento no qual a atmosfera ao redor do produto gradualmente se altera com o decorrer da estocagem, devido à ação do produto e à permeabilidade da embalagem. Este sistema de embalagem também pode ser definido como a embalagem de produtos perecíveis em atmosfera que sofreu modificação em sua composição, tornando-a diferente da composição do ar (LAURY; SEBRANEK, 2007).

A embalagem em AM consiste em trocar a composição do ar de um determinado recipiente (PARRY, 1995; WARREN et al., 1992). Assim, a atmosfera em torno do produto é substituída no momento do empacotamento por outra, especialmente preparada para cada tipo de alimento, o que permite controlar as reações químicas, enzimáticas e microbianas, evitando ou minimizando as principais degradações que são produzidas durante o período de armazenamento (RODRÍGUEZ, 1994). Alguns autores incluem nesse conceito tecnologias como embalagem a vácuo, inertização com $\mathrm{N}_{2}$, recobrimento de frutos com ceras ou outros revestimentos, que de alguma maneira irão mudar a micro ou macro-atmosfera ao redor do produto fresco (GILL, 1996).

Assim como outras técnicas de preservação de alimentos, o acondicionamento em AM foi descoberto ao acaso. No final do século XIX e início do século XX, o transporte marítimo de carcaças da Austrália para a Europa era feito sob refrigeração em dióxido de carbono $\left(\mathrm{CO}_{2}\right)$ sólido (gelo seco). Nessa situação, a estabilidade das carnes dava-se tanto pelo efeito conservador do resfriamento proporcionado pelo $\mathrm{CO}_{2}$ como pelo efeito inibidor do crescimento microbiano associado ao uso de $\mathrm{CO}_{2}$ em atmosferas modificadas. Naquela ocasião conhecia-se o efeito preservador do $\mathrm{CO}_{2}$ por sua ação refrigeradora, porém desconhecia-se seu mecanismo de ação sobre outros componentes do meio cárneo (MAGALHÃES, 2006). Ainda, segundo relatos de Laury e Sebranek (2007), ao final dos anos 30, 26\% da carne bovina da Austrália e 60\% da Nova Zelândia eram transportadas via marítima até o Reino Unido em grandes containers com atmosfera de $\mathrm{CO}_{2}$. Posteriormente, no início dos anos 80, com o desenvolvimento de materiais de embalagem facilitou-se o uso de atmosferas modificadas.

$\mathrm{Na}$ América do Norte, por volta de $85 \%$ das carnes frescas e a maioria das carnes processadas são distribuídas em embalagens que utilizam AM (JAY, 2005). Linares et al. (2008) relataram que de 2002 à 2004 o uso de atmosferas modificadas em carnes apresentou um aumento de $9 \%$ para $13 \%$.

Ainda que a oxidação lipídica e o crescimento microbiano sejam fatores importantes para prolongar a vida de prateleira, bem como aumentar a aceitabilidade de carnes frescas, os sistemas de AM em carnes foram prioritariamente desenvolvidos para preservar sua cor vermelho brilhante, que é determinada pelo estado químico do pigmento mioglobina (KENNEDY et al., 2004).

Rev. Acad., Ciênc. Agrár. Ambient., Curitiba, v. 7, n. 4, p. 469-482, out./dez. 2009 


\section{BIOQUÍMICA DA COR DA CARNE}

A conformação química e a concentração dos pigmentos heme, mais especificamente da mioglobina, são responsáveis pela cor da carne. A mioglobina é composta por uma cadeia polipeptídica denominada globina, que está acoplada a um grupo prostético denominado heme, composto por um átomo de ferro e um anel porfirínico (CLYDESDALE; FRANCIS, 1976). A cor de carnes frescas é definida pela quantidade relativa de três formas da mioglobina, que estão em constante equilíbrio dinâmico, sendo reversíveis e interconversíveis entre si (FOX, 1966).

Em carnes frescas, a mioglobina pode se encontrar em seu estado reduzido, chamada de deoximioglobina, que apresenta cor vermelho-púrpura. Também pode se encontrar na forma de oximioglobina, de cor vermelho brilhante, ou de metamioglobina, de cor marrom (RIZVI, 1981; CONFORTH, 1994).

$\mathrm{Na}$ ausência de $\mathrm{O}_{2}$, a mioglobina encontra-se na forma de deoximioglobina, apresentandose vermelho-púrpura. Quando a carne é exposta a atmosferas ricas em $\mathrm{O}_{2}$, a deoximioglobina passa para o estado de oximioglobina e desenvolve a cor vermelho brilhante. Ao longo de uma contínua exposição ao $\mathrm{O}_{2}$, há oxidação da oximioglobina à metamioglobina, que possui cor marrom, extremamente indesejável para a atratividade da carne (KENNEDY et al., 2004).

Altas pressões de $\mathrm{O}_{2}$ (40 torr) favorecem a reação de redução da mioglobina, que se converte em oximioglobina. Em pressões reduzidas de $\mathrm{O}_{2}(1,0$ a 1,4 torr), observa-se oxidação do ferro heme, que passa do estado ferroso $\left(\mathrm{Fe}_{2}^{+}\right)$ao seu estado férrico $\left(\mathrm{Fe}_{3}^{+}\right)$, com consequente formação de metamioglobina (McMILLIN, 2008).

Quando aproximadamente $50 \%$ da oximioglobina é convertida em metamioglobina, a carne torna-se inaceitável para a maioria dos consumidores. A metamioglobina pode ser reduzida à mioglobina pela ação de enzimas redutoras endógenas NADH dependentes. Este fenômeno é chamado de Metamyoglobin reducing activity (MRA). O cofator enzimático NADH é obtido de um processo de oxidação enzimática de substratos endógenos como a glicose, ainda presente em carnes frescas. Quando os substratos oxidáveis são suprimidos, o tecido perde seu poder redutor e o ferro do heme pigmento é oxidado à metamioglobina (LAWRIE, 2004).

\section{TIPOS DE ATMOSFERAS MODIFICADAS UTILIZADAS EM EMBALAGENS DE CARNES FRESCAS}

Goméz et al. (2001) citam que vários tipos de atmosferas e misturas de gases como $\mathrm{O}_{2}, \mathrm{~N}_{2}$, $\mathrm{CO}_{2}$, ozônio $\left(\mathrm{O}_{3}\right)$ e óxido de etileno $\left(\mathrm{C}_{2} \mathrm{H}_{4} \mathrm{O}\right)$ têm sido estudados com o objetivo de aumentar o tempo de vida útil dos alimentos.

No entanto, os sistemas mais empregados para carnes têm sido o empacotamento a vácuo e as combinações de $\mathrm{O}_{2}, \mathrm{~N}_{2}, \mathrm{CO}_{2}$ e CO. A proporção desses gases na mistura depende do tipo de produto cárneo, da temperatura de estocagem, das propriedades de barreira e da relação entre o espaço livre da embalagem e o peso do produto (JEREMIAH, 2001).

De acordo com Young et al. (1988), cada tipo de gás possui um papel específico na conservação da cor e no aumento da vida de prateleira da carne. Porém, independentemente da mistura de gases utilizada, em todos os sistemas de embalagens em atmosferas modificadas deve-se observar alguns fatores que influem na eficiência do sistema de conservação, como a permeabilidade do material da embalagem ao $\mathrm{O}_{2}$, ao $\mathrm{CO}_{2}$ e ao vapor d'água; a transmissão de $\mathrm{O}_{2}, \mathrm{CO}_{2}$, CO e vapor d'água pela região selada; a temperatura em que essa embalagem será armazenada; a área e a superfície do material da embalagem (TSIGARIDA; NICHAS, 2001).

Do ponto de vista regulatório, as atmosferas modificadas são consideradas coadjuvantes de fabricação e não aditivos. Sendo assim, sua utilização não necessita de declaração específica nos rótulos dos produtos (CORNFORTH; HUNT, 2008).

Rev. Acad., Ciênc. Agrár. Ambient., Curitiba, v. 7, n. 4, p. 469-482, out./dez. 2009 
Comercialmente, os principais sistemas de AM utilizados em carnes são os sistemas com alto teor de $\mathrm{O}_{2}$ e os sistemas ausentes de $\mathrm{O}_{2}$, como o envase a vácuo e os sistemas compostos por misturas de $\mathrm{CO}_{2}$ em altas concentrações, $\mathrm{N}_{2}$ e, mais recentemente, CO.

Em todos os sistemas de AM em que se faz a adição de $\mathrm{N}_{2}$, esse, por ser um gás inerte, possui a função única de preenchimento do volume na embalagem, não interferindo diretamente no alimento (MAGALHÃES, 2006; ZAKRYS et al., 2009).

\section{ATMOSFERAS MODIFICADAS COM ALTO TEOR DE $\mathrm{O}_{2}$}

Nos sistemas com alto teor de $\mathrm{O}_{2}$, a concentração desse gás nas embalagens é alta, normalmente acima de $70 \%$, sendo usualmente adicionado também $\mathrm{CO}_{2}$ à mistura, em baixas concentrações (WILKINSON et al., 2006). John et al. (2005) descrevem que a mistura de gases mais comumente empregada para a conservação de carnes frescas é $80 \%$ de $\mathrm{O}_{2}$ e $20 \%$ de $\mathrm{CO}_{2}$.

As embalagens com filmes permeáveis aos gases atmosféricos, como os filmes de cloreto de polivinil (PVC), ou ainda as com misturas de gases com altas concentrações de $\mathrm{O}_{2}$ têm o intuito de manter a cor vermelho brilhante em carnes frescas (GILL, 1991; LINARES et al., 2007). A principal vantagem do uso de atmosferas com alto teor de $\mathrm{O}_{2}$, em relação às embalagens tradicionais com filmes de PVC, é a maior estabilidade da cor vermelha das carnes, mantida por até 14 dias, quando comparada à estabilidade de quatro a sete dias nos filmes de PVC (JOHN et al., 2005). De Santos et al. (2007) afirmam que as atmosferas com alto teor de $\mathrm{O}_{2}$ têm sido largamente empregadas nas embalagens de carnes nos últimos 20 anos, em função da manutenção da coloração desejável nas carnes durante sua estocagem e distribuição por um período de 7 a 14 dias.

Nas atmosferas ricas em $\mathrm{O}_{2}$, os dois fatores mais importantes que limitam a vida de prateleira de carnes frescas são a cor e o crescimento microbiano. A oxidação lipídica ocupa o terceiro lugar em grau de importância na deterioração das carnes nesse tipo de atmosfera e impacta no desenvolvimento de odor rançoso quando a carne é cozida. Ainda que a oxidação lipídica tenha espaço na deterioração da carne, sua velocidade de reação é inferior à descoloração da mioglobina e ao crescimento microbiano (LAUZURICA et al., 2005; ZAKRYS et al., 2009).

A descoloração da mioglobina em embalagens permeáveis ao $\mathrm{O}_{2}$ ou na presença de $\mathrm{O}_{2}$ resulta de sua oxidação, que ocorre quando há redução da concentração de $\mathrm{O}_{2}$ e a carne permanece por longos períodos exposta a essa condição, levando à formação de metamioglobina e perdendo a aparência de frescor (KENNEDY et al., 2004).

Além da descoloração causada pela oxidação da mioglobina, (WILKINSON et al. (2006) relatam a existência de relação direta entre a atividade bacteriana e a descoloração da carne. O consumo de oxigênio por bactérias aeróbias, especialmente Pseudomonas, em atmosferas ricas em $\mathrm{O}_{2}$ na superfície da carne leva à rápida oxidação da mioglobina, devido à redução na pressão parcial de $\mathrm{O}_{2}$ no interior da embalagem.

Conforme descrito anteriormente, as principais desvantagens do alto teor de $\mathrm{O}_{2}$ em embalagens de carnes consistem no fato desse gás constituir uma atmosfera ideal para o crescimento de microrganismos aeróbios deteriorantes, bem como de estimular a oxidação dos lipídios da carne, resultando no desenvolvimento de odores indesejáveis (ZHAO et al., 1994; MAGALHÃES, 2006; ZAKRYS et al., 2009).

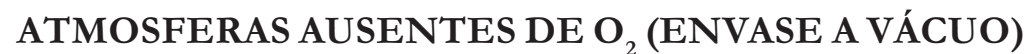

Para evitar os efeitos indesejáveis das atmosferas ricas em $\mathrm{O}_{2}$ em carnes frescas, o sistema de embalagem a vácuo tem sido amplamente utilizado; entretanto, também apresenta algumas desvantagens. $\mathrm{Na}$ ausência de $\mathrm{O}_{2}$, a cor da carne mostra-se de tom púrpura, resultante da formação de deoximioglobina, contrariando as expectativas dos consumidores pela não coloração vermelho brilhante

Rev. Acad., Ciênc. Agrár. Ambient., Curitiba, v. 7, n. 4, p. 469-482, out./dez. 2009 
na carne, atributo esse indicativo de frescor. Ainda que os sistemas a vácuo tenham custo acessível e sejam bastante efetivos na conservação de carnes, devido à inibição do crescimento microbiano aeróbio, as carnes embaladas nesse tipo de atmosfera apresentam como desvantagem o fato de não aparentarem frescor aos consumidores (JOHN et al., 2005; HUFFMAN; RILLEY, 2007). Além disso, devido à dificuldade em se retirar totalmente o $\mathrm{O}_{2}$ dessas embalagens, há uma crescente preocupação com o crescimento ou sobrevivência de microrganismos psicrotróficos microaerófilos patogênicos em carnes embaladas nesse sistema e mantidas sob refrigeração (GARCIA DE FERNANDO et al., 1995). Resíduos de $\mathrm{O}_{2}$ em embalagens a vácuo também podem resultar na formação de metamioglobina na superfície da carne, com consequente desenvolvimento da cor marrom (JOHN et al., 2005).

Além do sistema a vácuo, outros sistemas de atmosferas ausentes de O2 têm sido empregados em carnes frescas, na tentativa de aumentar o período de estocagem desses produtos, em função da redução do crescimento microbiano deteriorador, principalmente com o uso de atmosferas de $\mathrm{CO}_{2}$, e/ou de reduzir as deficiências do sistema a vácuo, no que se refere à cor da carne, como é o caso dos sistemas que utilizam atmosferas de CO.

\section{ATMOSFERAS MODIFICADAS COM BAIXO TEOR DE $\mathrm{O}_{2}$}

\section{Atmosferas com $\mathrm{CO}_{2}$}

$\mathrm{O} \mathrm{CO}_{2}$ exerce um forte efeito inibidor sobre o crescimento bacteriano. Sua ação se incrementa a baixas temperaturas, devido ao aumento de sua solubilidade $(179,9 \mathrm{~mL} / 100 \mathrm{~mL}$ de água a $\left.0^{\circ} \mathrm{C}\right)$. A depender da concentração empregada $(25 \%$ a $100 \%)$, o $\mathrm{CO}_{2}$ pode ser utilizado para o empacotamento em atmosferas de diferentes produtos. A absorção desse gás depende em grande parte do grau de umidade e gordura dos produtos (MORAL, 1993).

$\mathrm{O}$ efeito inibidor do $\mathrm{CO}_{2}$ sobre os microrganismos deve-se ao aumento do tempo de fase lag (de adaptação) do crescimento microbiano e do decréscimo da taxa de desenvolvimento bacteriano na fase logarítmica de crescimento. $\mathrm{O}$ efeito bacteriostático do $\mathrm{CO}_{2}$ na carne é influenciado pela concentração desse gás, pela contagem microbiana inicial e pela temperatura de estocagem (MARTíNEZ et al., 2005).

Atmosferas contendo $\mathrm{CO}_{2}$ são efetivas contra as bactérias aeróbias gram-negativas de decomposição, como Pseudomonas, que causam perda de cor e mau odor em carnes vermelhas, aves e pescados (PARRY, 1995). Contudo, Gill e Tan (1980) afirmam que a ação do $\mathrm{CO}_{2}$ contra esses microrganismos é efetiva somente em concentrações de $20 \%$ a $30 \%$, e que o aumento na concentração desse gás apresenta pouco efeito inibitório adicional sobre esse tipo de bactéria.

Pérez Mateos e Borderias (1997) relatam que o $\mathrm{CO}_{2}$ não retarda o crescimento de todos os microrganismos, além de ter pouco efeito sobre as leveduras, podendo ainda favorecer o crescimento de bactérias lácticas quando na composição de atmosferas com baixo teor de $\mathrm{O}_{2}$, haja vista seu metabolismo microaerófilo. Sorheim et al. (2004) citam que em atmosferas anaeróbias altas concentrações de $\mathrm{CO}_{2}$, que alcançam até $100 \%$, podem ser utilizadas com efeitos positivos na inibição de Lactobacillus e enterobactérias.

Mediante a seleção de níveis apropriados de $\mathrm{CO}_{2}$, é possível não apenas retardar o crescimento total da microbiota contaminante, como também alterar sua composição, de maneira a se obter um retardo seletivo de microrganismos com alto potencial deteriorador e que crescem rapidamente, o que significa uma maior vida útil para o alimento (LUÑO et al., 2000). Laury e Sebranek (2007) reportam que altas concentrações de $\mathrm{CO}_{2}$ em atmosferas modificadas têm mostrado redução no crescimento microbiano.

Silliker et al. (1977) verificaram que a estimativa da vida útil da carne suína e bovina baseada na cor é menor em relação à vida útil definida por parâmetros microbiológicos. Em seus estudos, a carne suína exibiu boa coloração durante 14 dias em atmosfera com $50 \%$ de $\mathrm{CO}_{2}$, enquanto que a carne bovina escureceu depois do quarto dia de estocagem, sem mostrar deterioração microbiana, provavelmente devido à substancial diferença no teor de mioglobina apresentado por ambas as carnes. Já Clarck e Lentz

Rev. Acad., Ciênc. Agrár. Ambient., Curitiba, v. 7, n. 4, p. 469-482, out./dez. 2009 
(1972) e Taylor (1985) verificaram que as concentrações de $15 \%$ a $20 \%$ de $\mathrm{CO}_{2}$ retardaram o crescimento microbiano sem causar problemas de descoloração em carne bovina.

Embora $\mathrm{o} \mathrm{CO}_{2}$ apresente comprovados efeitos benéficos na preservação da deterioração microbiana de carnes em concentrações de $10 \%$ a $20 \%$, estudos mostram que em concentrações maiores (acima de 30\%) o $\mathrm{CO}_{2}$ pode acelerar a descoloração de carnes frescas, devido ao seu efeito pró-oxidante (LAUZURICA et al., 2005; MARTÍNEZ et al., 2005; DE SANTOS, 2007). Outra causa provável para a descoloração de carnes verificada em atmosferas com alto teor de $\mathrm{CO}_{2}$ é seu efeito na redução do pH desses produtos, que controla a deterioração microbiana, porém promove a oxidação da mioglobina e dos lipídeos (MARTÍNEZ et al., 2005). A relação entre o aumento da oxidação lipídica e a redução do pH da carne é reforçada por Juncher et al. (2001), que observaram um decréscimo nos valores de ácido tiobarbitúrico - indicadores de rancificação lipídica na carne suína - com o aumento do pH da carne.

\section{Atmosferas com CO}

O uso do $\mathrm{CO}$ em embalagens de carnes iniciou-se como resposta à demanda dos consumidores por carnes de coloração atrativa e com aparência de frescor, mantendo essas características por longos períodos de estocagem (HUFFMAN; RILLEY, 2007).

Com a adição de $0,4 \%$ de $\mathrm{CO}$ em atmosferas modificadas, cortes de carne bovina armazenados sob refrigeração a $2^{\circ} \mathrm{C}$ mantiveram a cor vermelho brilhante por até 21 dias, quando comparados a cortes estocados a vácuo que apresentaram cor marrom superficial após 14 dias (JOHN et al., 2005).

McMillin (2008) relata que carne mantida sob refrigeração a $4^{\circ} \mathrm{C}$ em atmosfera com CO $(0,4 \%)$ apresenta vida de prateleira de 35 dias, enquanto que essa, quando submetida a atmosfera com alto teor de $\mathrm{O} 2(80 \%)$, apresenta vida de prateleira de 12 a 16 dias, e de 5 a 7 dias, quando embalados em filmes de PVC. Para a carne moída mantida sob essas mesmas condições, a vida de prateleira em sistema com CO é de 28 dias, 10 a 12 dias com alto teor de $\mathrm{O}_{2}$, e 2 a 3 dias em embalagem com filme de PVC. Jayasingh et al. (2001) observaram que cortes de carne bovina, bem como carne bovina moída estocados em sistema com $0,5 \%$ de CO, mantiveram a cor vermelha estável por até oito semanas de armazenamento.

A primeira utilização comercial do $\mathrm{CO}$ em embalagens de carne fresca foi registrada na Noruega, em 1985. Naquela ocasião, o sistema utilizava mistura gasosa de $0,3 \%$ a $0,5 \%$ de CO, $60 \%$ a $70 \%$ de $\mathrm{CO}_{2}$ e $30 \%$ a $40 \%$ de $\mathrm{N}_{2}$, nas embalagens primárias de carne bovina, suína e ovina. Esse sistema de condições anaeróbicas combinava reduzidos teores de $\mathrm{CO}$ e altos teores de $\mathrm{CO}_{2}$ (SORHEIM et al., 1999; WILKINSON et al., 2006; CORNFORTH; HUNT, 2008). Segundo VENTURINI (2007), até o ano de 2004 as embalagens com misturas gasosas contendo baixos teores de $\mathrm{CO}(0,4 \%)$ representavam cerca de $60 \%$ das vendas ao varejo de carne vermelha na Noruega.

Nos Estados Unidos, em 2002 o CO foi classificado como GRAS (substância geralmente reconhecida como segura) pelo Food and Drug Administration (FDA) para uso comercial em concentrações inferiores a $0,4 \%$ em embalagens secundárias, de transporte (masterpack) de carnes de todas as espécies animais. Nessas embalagens, o CO deve ser utilizado em sistema anaeróbico em combinações com $30 \%$ de $\mathrm{CO}_{2}$ e balanço restante de $\mathrm{N}_{2}$ (JOHN et al., 2005). O CO também foi aprovado para uso similar na Austrália e Nova Zelândia, onde é considerado um coadjuvante de fabricação no processamento de carnes frescas (WILKINSON et al., 2006).

Posteriormente, em 2004 o FDA classificou como GRAS o uso de CO em concentração máxima de $0,4 \%$ em embalagens primárias de carne, nas quais a mistura de gases é insuflada diretamente sobre o alimento no interior da embalagem (DE SANTOS et al., 2007; LINARES et al., 2008).

A aplicação comercial do CO em carnes pode ser realizada de duas formas. O CO pode ser utilizado como pré-tratamento ao envase a vácuo, mediante a aspersão sobre a superfície da carne fresca, em concentrações que variam de $5 \%$ a $100 \%$, para manter a atratividade da cor vermelha durante o acondicionamento a vácuo (BREWER et al., 1994; JAYASINGH et al., 2001; WILKINSON et al., 2006). Jayasingh et al. (2001) relatam que cortes de carne bovina pré-tratados com $5 \%$ de CO por 24 horas, e posteriormente estocados a vácuo, mantiveram a cor vermelha durante cinco semanas. A outra

Rev. Acad., Ciênc. Agrár. Ambient., Curitiba, v. 7, n. 4, p. 469-482, out./dez. 2009 
forma de utilização do CO, que é a mais comumente empregada, é sua aplicação como componente da mistura de gases que permanece em contato direto com a carne nos sistemas de AM (WILKINSON et al., 2006; CORNFORTH; HUNT, 2008).

O emprego do CO nas atmosferas modificadas em carnes tem como objetivos manter a atratividade da carne e evitar o efeito degradativo causado por grandes concentrações de $\mathrm{O}_{2}$. A presença do $\mathrm{CO}$ em sistemas com baixo teor ou ausentes de $\mathrm{O}_{2}$ permite, além do aumento da vida útil, a prevenção de processos oxidativos que resultam em alterações indesejáveis de sabor, aroma e escurecimento da carne. Quando a cor da carne torna-se marrom, também perde seu aroma característico; ou seja, nesse sentido, a prevenção da oxidação também preserva o odor típico da carne fresca (HUFFMAN; RILLEY, 2007).

$\mathrm{O}$ efeito do $\mathrm{CO}$ sobre a cor da carne é resultante da formação de carboximioglobina. A carboximioglobina é formada pela ligação da mioglobina em seu estado natural (deoximioglobina) com o CO, produzindo cor vermelho brilhante na carne, altamente atrativa (DE SANTOS et al., 2007). Esse pigmento, além de possuir coloração vermelha aparentemente indistinguível da oximioglobina (tanto a olho nu quanto utilizando métodos espectrofotométricos), é mais estável em relação à mesma. Com o uso do $\mathrm{CO}$ em embalagens de $\mathrm{AM}$, a necessidade da presença de $\mathrm{O}_{2}$ para manutenção da cor vermelha brilhante de carnes é eliminada (HUFFMAN; RILEY, 2007).

A afinidade da deoximioglobina pelo $\mathrm{CO}$ é de 28 a 51 vezes superior à sua afinidade pelo $\mathrm{O}_{2}$. Adicionalmente, o $\mathrm{CO}$ pode remover $\mathrm{O}_{2}$ da oximioglobina, ligando-se a essa (DE SANTOS et al., 2007). Contudo, Huffman e Riley (2007) afirmam que a adição de pequenas quantidades de CO não converte a cor marrom da carne (metamioglobina) em vermelha (carboximioglobina).

Segundo Moller e Skibsted (2006), a adição de baixas concentrações de CO em atmosferas com residual de $\mathrm{O}_{2}$ pode restaurar a cor vermelha das carnes através de sua forte ligação com o íon ferroso da mioglobina, eliminando os problemas de descoloração decorrentes de períodos prolongados de estocagem com baixos teores de $\mathrm{O}_{2}$

Sorheim et al. (1999) afirmam que as diferenças em relação ao aumento da vida de prateleira das carnes embaladas em AM com baixas concentrações de CO são determinadas pelo método de embalagem, pela temperatura de estocagem e, ainda, pela carga microbiológica inicial da carne.

A propriedade do $\mathrm{CO}$ de manter a estabilidade da cor vermelha brilhante em carnes frescas possibilita que as mesmas mantenham-se atrativas durante longos períodos de estocagem, reduzindose perdas econômicas e de produto. Seu uso no envase de carnes pode estimular ainda mais uma tendência de comércio de carnes frescas, que consiste na distribuição de carnes em sua embalagem final (case-ready), pronta para a exposição ao consumidor, a partir da indústria processadora, sem necessitar de manipulação e/ou re-embalagem no âmbito varejista. O comércio desse tipo de carne embalada (caseready) é bastante comum para as carnes de frango, sendo também uma tendência de mercado para as carnes de outras espécies animais, principalmente a bovina e a suína. Hunt et al. (2007) citam dados de uma pesquisa realizada nos EUA pelas indústrias de carnes bovina e suína, que mostra que em 2004 as carnes frescas dessas espécies animais comercializadas em suas embalagens finais, a partir da indústria processadora, já representavam $60 \%$ do mercado de carnes frescas naquele país.

A carboximioglobina é mais estável à desnaturação térmica em relação à deoximioglobina. Dessa forma, sua desnaturação, com consequente mudança de coloração do vermelho para o marrom durante a cocção, ocorre em temperaturas mais altas $\left(>82^{\circ} \mathrm{C}\right)$. Por essa razão, as carnes contendo carboximioglobina aparentam estar menos cozidas em relação às carnes contendo deoximioglobina, quando aquecidas à mesma temperatura. Essa situação é verificada mesmo se sabendo que durante a cocção de carnes até $85 \%$ do CO ligado à mioglobina é perdido (JOHN et al., 2005; DE SANTOS et al., 2007). Suman et al. (2009) relatam que, entre as formas de mioglobina encontradas em carnes submetidas a atmosferas modificadas, a resistência à desnaturação térmica ocorre na seguinte ordem decrescente: carboximioglobina $>$ deoximioglobina $>$ oximioglobina > metamioglobina. Essa estabilidade da carboximioglobina ao calor pode ser uma vantagem para a segurança alimentar, uma vez que a oximioglobina presente em atmosferas ricas em $\mathrm{O}_{2}$ pode contribuir para o aparecimento prematuro da cor marrom, característica de carne cozida, quando a mesma é submetida ao calor, resultando em aparência de carne bem passada, ainda

Rev. Acad., Ciênc. Agrár. Ambient., Curitiba, v. 7, n. 4, p. 469-482, out./dez. 2009 
que a temperatura não tenha atingido um valor mínimo para a destruição microbiana (DE SANTOS et al., 2007; SUMAN et al., 2009).

Geralmente, os consumidores tendem a confiar apenas na cor marrom das carnes cozidas como um indicativo de que foram bem cozidas e que, dessa forma, houve destruição microbiana e são seguras para o consumo. Nos EUA, recomenda-se que a carne seja cozida a uma temperatura mínima de $71^{\circ} \mathrm{C}$ para garantir sua segurança microbiológica. No entanto, carne estocada em atmosferas com alto teor de $\mathrm{O}_{2}$ e, portanto, com alto teor de oximioglobina, pode desenvolver a cor marrom à temperatura de $57^{\circ} \mathrm{C}$, insuficiente para garantir a destruição microbiana (JOHN et al., 2005).

De Santos et al. (2007) verificaram que cortes cárneos suínos embalados em atmosfera com $0,36 \%$ de $\mathrm{CO}$ e posteriormente cozidos mantiveram a coloração rosada em seu interior, mesmo após atingir temperatura interna de $82^{\circ} \mathrm{C}$. Esses mesmos autores citam que, em trabalho realizado por Ballard (2004), somente $49 \%$ da carboximioglobina foi desnaturada em temperatura de $71,1^{\circ} \mathrm{C}$. Essas situações são justificadas pela grande resistência térmica da carboximioglobina e pela suposta proteção antioxidante do átomo de ferro $\left(\mathrm{Fe}^{2+}\right)$ proporcionada pela ligação carbonila do CO com a mioglobina, mesmo após a desnaturação térmica do grupamento globina dessa molécula. John et al. (2005) observaram a manutenção da cor avermelhada no interior de cortes cárneos bovinos submetidos à atmosfera com $\mathrm{CO}$ após cocção com a temperatura interna da carne de $79^{\circ} \mathrm{C}$.

Autores como Martínez et al. (2005) e Linares et al. (2007) relatam que o CO também apresenta efeito antioxidante sobre os lipídeos de embutidos. Martínez et al. (2005) constataram menores valores de oxidação lipídica em salsichas estocadas sob refrigeração por 20 dias em atmosfera contendo 0,3\% de $\mathrm{CO}$ e $30 \%$ de $\mathrm{CO}_{2}$. Os mesmos autores ainda citam que as salsichas mantidas em atmosfera contendo $\mathrm{CO}$ retardaram o crescimento microbiano em velocidade semelhante à obtida na presença de $60 \%$ de $\mathrm{CO}_{2}$. Deduz-se que esses resultados provavelmente ocorreram devido ao efeito somatório da presença de $\mathrm{CO}$ e de $\mathrm{CO}_{2}$ e da ausência de $\mathrm{O}_{2}$ nas embalagens.

Luño et al. (1998) constataram que bifes de carne bovina mantidos em atmosfera contendo $1 \%$ de $\mathrm{CO}, 24 \%$ de $\mathrm{O}_{2}, 50 \%$ de $\mathrm{CO}_{2}$ e $25 \%$ de $\mathrm{N}_{2}$ apresentaram reduzida contaminação por bactérias psicrotróficas. Os mesmos autores também verificaram que a estabilidade da cor nos bifes de carne bovina e na carne moída foi mantida por 29 dias, quando estocados em atmosfera contendo CO (1\% de $\mathrm{CO}, 70 \%$ de $\mathrm{O}_{2}, 20 \%$ de $\mathrm{CO}_{2}$ e $9 \%$ de $\mathrm{N}_{2}$ ).

Uma das controvérsias com o uso do CO está na possibilidade de engano do consumidor na aquisição de carnes aparentemente frescas devido à sua cor, porém, em estado de deterioração, visto que a forte estabilidade da ligação do CO com os pigmentos da carne (mioglobina e hemoglobina do sangue residual) lhe conferem cor vermelha, mesmo após a contagem de bactérias deteriorantes atingir número suficiente para sua condenação (WILKINSON et al., 2006). No entanto, a deterioração bacteriana das carnes pode ser evitada pelo uso de baixas temperaturas durante seu período de estocagem. Além disso, as embalagens adicionadas de CO devem apresentar ao consumidor declaração de prazo de validade claramente definido, indicando a data limite para o consumo do produto. Mesmo nas ocasiões em que as carnes embaladas com CO tenham permanecido em temperatura inadequada, ocorrendo sua deterioração precoce antes da expiração do prazo de validade, vários sinais podem alertar os consumidores sobre a sanidade desses produtos. O estufamento nas embalagens pode indicar a multiplicação de bactérias deteriorantes, bem como a presença de odor característico de deterioração e aspecto e textura limosa ou viscosa, facilmente perceptíveis. Esses são sinais típicos de deterioração associados pelos consumidores às carnes que não devem ser consumidas (HUNT et al., 2007). Esses dados corroboram com os achados de Martínez et al. (2005), que verificaram manutenção da cor vermelha por 20 dias em salsichas mantidas sob refrigeração em atmosfera contendo $0,3 \%$ de $\mathrm{CO}$ e $30 \%$ de $\mathrm{CO}_{2}$, porém, com perda do odor de frescor após 16 dias de estocagem.

Portanto, os sistemas de AM com adição de CO não reduzem ou eliminam a necessidade de refrigeração, havendo um efeito sinérgico entre essas tecnologias de conservação de carnes. O controle rígido de temperatura durante todo o ciclo de preparo, distribuição e comercialização do produto é um fator decisivo para o sucesso da aplicação de embalagens com AM (SARANTÓPOULOS et al., 1998; FEIJÓ et al., 2006; LINARES et al., 2008).

Rev. Acad., Ciênc. Agrár. Ambient., Curitiba, v. 7, n. 4, p. 469-482, out./dez. 2009 
Outra controvérsia com o emprego do CO reside na alta toxicidade desse gás quando inalado. Os efeitos deletérios do $\mathrm{CO}$ ocorrem devido à maior afinidade da hemoglobina nas células vermelhas do sangue com o $\mathrm{CO}$ em relação ao $\mathrm{O}_{2}$, impedindo o transporte desse gás aos tecidos. Em concentrações de 2,5\% de carboxihemoglobina no sangue, os indivíduos com problemas cardiovasculares podem apresentar alterações na função cardíaca. No entanto, em adultos saudáveis, nenhum efeito adverso foi descrito com concentrações de até 5\% de carboxihemoglobina ou com a exposição de indivíduos à atmosfera com CO em níveis inferiores a 35 ppm por uma hora (CORNFORTH; HUNT, 2008).

Apesar dos efeitos positivos do CO sobre a estabilidade da cor vermelha das carnes serem conhecidos há mais de cem anos, a preocupação com a toxicidade do $\mathrm{CO}$ aos seres humanos fez com que, na ocasião dos primeiros ensaios com esse gás em embalagens de carne, sua aplicação comercial não fosse considerada viável devido aos possíveis riscos para os trabalhadores (CORNFORTH; HUNT, 2008).

Industrialmente, os sistemas que utilizam $\mathrm{CO}$ não representam risco aos operadores de plantas de embalagens de carnes, visto que as misturas de gases são preparadas previamente pelo fabricante e entregues em cilindros com os gases pressurizados. No processo de embalagem, o espaço de ar da embalagem é removido com o uso de vácuo, a mistura gasosa é insuflada e a embalagem rapidamente termo-selada. Nessa operação praticamente não há escape de CO para o ambiente. Ainda assim, as instalações devem ser bem ventiladas e equipadas com detectores de CO, conforme recomendam os protocolos normais de segurança ambiental (CORNFORTH; HUNT, 2008).

Em relação à segurança do CO aos consumidores, Cornforth e Hunt (2008) afirmam que a quantidade de $\mathrm{CO}$ presente nas embalagens é muito baixa para causar danos à saúde, quer seja no momento de abertura das mesmas para o consumo das carnes ou durante seu cozimento. A Agência Americana de Proteção Ambiental estabelece como limite de CO para a qualidade do ar o valor máximo de 9 ppm por um período de 8 horas de inalação. Dessa forma, para embalagens contendo 0,4\% de CO em um volume de 1,5 litro, abertas em local com área de $150 \mathrm{~m}^{3}$, seria necessária a abertura de 216 embalagens para ultrapassar o padrão de qualidade do ar estabelecido para a inalação de $5 \mathrm{~m}^{3}$ de ar por pessoa. Caso em uma refeição fosse consumida uma grande quantidade de carne (250 g) e todas as emissões de $\mathrm{CO}$ da embalagem permanecessem vinculadas à carne após sua cocção, o consumidor inalaria apenas 3,5\% do nível máximo seguro de CO em 8 horas. Na prática, a quantidade de CO inalada por refeição seria muito menor, visto que apenas $15 \%$ do $\mathrm{CO}$ permanecem vinculados à carne após seu cozimento. Também é improvável que todo o CO ingerido seja absorvido. Nesse sentido, a exposição ao $\mathrm{CO}$ no processo de abertura da embalagem ou quando do consumo da carne é muito inferior ao limite recomendado pelas normas de segurança (CORNFORTH; HUNT, 2008).

De acordo com Sorheim et al. (1997), concentrações de 0,5\% de CO não representam nenhuma ameaça toxicológica para os consumidores, pois níveis abaixo de 1\% de CO resultam em quantidades desprezíveis de carboximioglobina na corrente sanguínea. Linares et al. (2008) citam que concentrações de 0,4 a $1 \%$ de $\mathrm{CO}$ em atmosferas modificadas são completamente seguras para o consumo humano.

Ainda que tenha sido comprovada a segurança do CO em baixas concentrações em atmosferas modificadas para carnes frescas, sua utilização gera discussões em vários países. Após 19 anos de bem sucedida aplicação comercial, o uso do CO foi descontinuado na Noruega em 2004, em obediência às normas europeias de comércio de carnes, definidas por exigências dos países que realizam comércio de carnes com aquele país. Atualmente, o CO é considerado na Europa um aditivo alimentar e, por isso, deve ser declarado nas embalagens de carne em atmosferas onde está presente (WILKINSON et al., 2006).

Apesar dessas controvérsias, o CO tem sido utilizado comercialmente nos EUA e em outros países em embalagens de carnes frescas, como alternativa vantajosa sobre as demais atmosferas com baixo teor de $\mathrm{O}_{2}$ como o envase a vácuo, ou com alto teor de $\mathrm{CO}_{2}$, devido às suas propriedades benéficas sobre a atratividade e a extensão de vida de prateleira das carnes frescas. 


\section{CONSIDERAÇÕES FINAIS}

Para a conservação de carnes frescas, as embalagens com atmosferas modificadas têm sido consideradas um dos sistemas mais efetivos na manutenção da estabilidade sensorial e microbiológica desses produtos. Ainda que no Brasil o sistema de AM mais empregado para a conservação de carnes seja o envase a vácuo, devido principalmente à sua eficiência na inibição de microrganismos aeróbios e seu baixo custo, esse sistema não proporciona aparência de frescor às carnes, que se mostram escurecidas quando estocadas nesse tipo de atmosfera. Tendo em vista que a cor da carne é o atributo que lhe confere aparência de frescor, outros tipos de AM têm sido utilizados em carnes frescas para torná-las mais atrativas aos consumidores. Entre esses sistemas, destaca-se o emprego de atmosferas compostas por pequenas concentrações de $\mathrm{CO}$, que possui a capacidade de se ligar fortemente à mioglobina da carne, proporcionando-lhe cor vermelho brilhante altamente estável e atrativa. Além disso, as atmosferas compostas de $\mathrm{CO}_{2}, \mathrm{~N}_{2}$ e pequenas quantidades de $\mathrm{CO}$ retardam a deterioração microbiana e previnem os processos oxidativos na carne, mantendo seu sabor e aroma. Apesar da característica tóxica do CO, seu emprego em concentração igual ou inferior a $0,4 \%$ na composição de atmosferas modificadas não representa risco à saúde dos consumidores ou dos operadores do sistema. Por isso, o uso do CO é considerado bastante promissor em embalagens de carnes frescas, sendo utilizado comercialmente em diversos países. Independente do tipo de AM empregado para a conservação de carnes frescas, é importante ressaltar que esses sistemas de embalagem não reduzem ou eliminam a necessidade de refrigeração dos produtos, havendo um efeito sinérgico entre essas tecnologias de conservação destes produtos. Dessa forma, o controle rígido da temperatura e da higiene durante toda a cadeia produtiva da carne é essencial para o sucesso da aplicação de embalagens com AM.

\section{REFERÊNCIAS}

BARACAT, R. S. Avaliação do processo por embalagem do tipo atmosfera modificada na conservação da carne bobina porcionada. 2006. 72 f. Tese (Doutorado em Zootecnia) - Faculdade de Zootecnia e Engenharia de Alimentos, Universidade de São Paulo, Pirassununga, 2006.

BALLARD, C. Thermal denaturation of carboxymyoglobin and the effect of carbon monoxide and injection enhancement on display and cooked color. 2004. Master's Thesis (Master's Food Science) - Kansas State University, Manhattan, KS, 2004.

BREWER, M. S. et al. Carbon monoxide effects on color and microbial counts of vacuum packaged beef steaks in refrigerated storage. Journal of Food Quality, Urbana, v. 17, n. 3, p. 231-236, 1994.

CLARCK, D. S.; LENTZ, C. P. Use of carbon dioxide for extending shelf-life of pre-packaged beef. Canadian Institute of Food Science Technology Journal, v. 9, n. 3, p. 114-119, 1972.

CLYDESDALE, F. M.; FRANCIS, F. J. Pigments. In: FENNEMA, O. R. (Ed). Principles of Food Science. Part I: Food Chemistry. 11th ed. New York: Marcel Dekker, Inc., 1976. p. 393-402.

CORNFORTH, D. Color: its basis and importance. In: PEARSON, A. M.; DUTSON, T. R. Advances in meat research: quality attributes and their measurement in meat, poultry and fish products. New York: AVI Book, 1994. p. 49-88.

CORNFORTH, D; HUNT, M. Low-oxygen packaging of Fresh Meat with carbon monoxide. Meat quality, microbiology, and safety. American Meat Science Association, v.1, n. 2, p. 1-10, 2008. 
DE SANTOS, F. et al. Effect of carbon monoxide in modified atmosphere packaging storage time and endpoint cooking temperature on the internal color of enhanced pork. Meat Science, United States, v. 77, n. 4, p. 520-528, 2007.

FEIJÓ, M. B. S. et al. Efeitos da embalagem em atmosfera modificada na conservação e aumento da vida útil de carne de avestruz (Struthio camellus). In: FEIJÓ, M. B. S. Proposta de padronização dos cortes, avaliação nutricional, parâmetros de qualidade e efeito da embalagem em atmosfera modificada na conservação da carne de avestruz (Strutbio camellus) obtida em abate experimental. 2006. 145 f. Tese (Programa de Pós-Graduação em Vigilância Sanitária) Fundação Oswaldo Cruz, Rio de Janeiro, 2006.

FOX, J. B. The chemistry os meat pigments. Journal of Agricultural and Food Chemistry, Philadelphia, v. 14, n. 3, p. 207-210, 1966.

GARCIA DE FERNANDO, G. D. et al. Growth/survival of psychotropic pathogens on meat packaged under modified atmospheres. International Journal of Food Microbiology, Madrid, v. 28, n. 2, p. 221-231, 1995.

GILL, C. O. Extending the storage life of meat: preservative atmospheres. Wuesten Canada Research Group on extended storage of meat and meat products. Technical Bulletin Departament of Applied Microbiology and Food Science, Saskatoon, n. 1, 1991.

GILL, C. O. Extending the storage life of raw chiled meats. Meat Science, Alberta, v. 43, n. 1, p. 99-109, 1996.

GILL, C. O.; TAN, K. H. Effect of carbon dioxide on growth of meat spoilage bacteria. Applied and Environmental Microbiology, Hamilton, v. 39, n. 2, p. 317-319, 1980.

GOMÉZ, G. R. et al. Envase y embalaje: envasado de alimentos. Aspectos técnicos del envasado al vacío y bajo atmósfera protectora. Alimentación, Equipos y Tecnología, v. 20, n. 1, p. 75-84, 2001.

HUFFMAN, R. D.; RILLEY, J. M. Low-Oxygen Packaging with CO: a study in food politics that warrants peer review. Food Safety Magazine, p. 1-6, 2007.

HUNT, M. et al. Case-ready meats modified atmosphere packaging. Fact Sheet. American Meat Institute, Washington, 2007. Disponível em: <http://www.meatami.com>. Acesso em: 11 jul. 2008.

JAY, J. M. et al. Modern food microbiology. New York: Springer Science \& Business Media, 2005.

JAYASINGH, P. et al. Evaluation of carbon monoxide (CO) treatment in modified atmosphere packaging or vacuum packaging to increase color stability of fresh beef. Meat Science, Logan, v. 59, n. 3, p. 317-324, 2001.

JEREMIAH, L. E. Packaging alternatives to deliver fresh meat using short or long-term distribution. Food Research International, Alberta, v. 34, n. 9, p. 749-772, 2001.

JOHN, L. et al. Color and thiobarbituric acid values of cooked top sirloin steaks packaged in modified atmospheres of $80 \%$ oxygen, or $0,4 \%$ carbon monoxide, or vacuum. Meat Science, Elsevier, v. 69, n. 3, p. 441-449, 2005.

JUNCHER, D. et al. Effect of pre-slaughter physiological conditions on the oxidative stability of color and lipid oxidation during chill storage of pork. Meat Science, Frederiksberg C, v. 58, n. 4, p. 347-357, 2001.

KENNEDY, C. et al . Display life of sheep meats retail packaged under atmospheres of various volumes and compositions. Meat Science, Cork, v. 68, n. 4, p. 649-658, 2004. 
LAURY, A.; SEBRANEK, J. G. Use of carbon monoxide combined with carbon dioxide for modified atmosphere packaging of pre and postrigor fresh pork sausage to improve shelf life. Journal of Food Protection, Ames, v. 70, n. 4, p. 937-942, 2007.

LAUZURICA, S. et al. Effect of dietary supplementation of vitamin E on characteristics of lamb meat packed under modified atmosphere. Meat Science, Madrid, v. 70, n. 4, p. 639-646, 2005.

LAWRIE, R. A. Ciência da carne. 6. ed. Porto Alegre: Artmed, 2004.

LINARES, M. B. et al. Lipid oxidation in lamb meat: Effect of the weight, handling previous slaughter and modified atmospheres. Meat Science, Albacete, v. 76, n. 4, p. 715-720, 2007.

Effect of stunning systems on meat quality of Manchego suckling lamb packed under modified atmospheres. Meat Science, Albacete, v. 78, n. 3, p. 279-287, 2008.

LUÑO, M. et al. Shelf-life extension and colour stabilization of beef packaged in a low $\mathrm{O}_{2}$ atmosphere containing CO: loin steaks and ground meat. Meat Science, Zaragoza, v. 48, n. 1/2, p. 75-84, 1998.

Beef shelf life in low $\mathrm{O}_{2}$ in high $\mathrm{CO}_{2}$ atmospheres containing different low $\mathrm{CO}$ concentrations. Meat Science, Zaragoza, v. 55, n. 4, p. 413-419, 2000.

MAGALHÃES, A. U. Avaliação do uso de atmosferas modificadas em porcionados de suínos. 2006. 58 f. Dissertação (Mestrado em Ciência e Tecnologia de Alimentos) - Universidade Federal de Santa Maria, Santa Maria, 2006.

MARTÍNEZ, L. et al. Effect of different concentrations of carbon dioxide and low concentration of carbon monoxide on the shelf-life of fresh pork sausages packaged in modified atmosphere. Meat Science, Zaragoza, v. 71, n. 3, p. 563-570, 2005.

McMILLIN, K. W. Where is MAP going? A review and future potential of modified atmosphere packaging for meat. Meat Science, Louisiana, v. 80, n. 1, p. 43-65, 2008.

MOLLER, J. K. S.; SKIBSTED, L. H. Myoglobins: the link between discoloration and lipid oxidation in muscle and meat. Química Nova, Frederiksberg C, v. 29, n. 6, p. 1270-1278, 2006.

MORAL, A. Aspectos sobre refrigeración y conservación de pescados envasados en atmosferas modificadas para su venta detallista. Alimentación, Equipos y Tecnología, Madrid, v. 12, n. 1, p. 101-104, 1993.

NISHI, L. M.; FARIA, A. F. Composições gasosas en sistemas de embalagens com atmosfera modificada para carne bovina. Revista Nacional da Carne, São Paulo, n. 353, p. 54-59, 2006.

PARRY, R. T. Envasado de alimentos en atmósferas modificadas. Madrid: A. Madrid Vicente, 1995.

PÉREZ MATEOS, M.; BORDERIAS, A. J. Nuevas tecnologías destinadas a prolongar el tiempo de conservación de los productos pesqueros refrigerados. Alimentación, Equipos y Tecnología, v. 6, n. 1, p. 79-84, 1997.

RIZVI, S. S. H. Requerements for foods packages in polymeric films. CRC Critical reviews in Food Science and Nutrition, West Palm Beach, v. 14, n. 2, p. 111-134, 1981.

RODRÍGUEZ, G. M. Envasado bajo atmósfera protectora: aplicación a la industria hortofrutícola. Alimentación, Equipos y Tecnología, Bilbao, v. 13, n. 1, p. 43-49, 1994.

SARANTÓPOULOS, C. I. G. L. et al. Embalagens com atmosfera modificada. 2. ed. Campinas: CETEA/ITAL, 1998. 
SILLIKER, J. H. et al. Preservation of refrigerated meat with controlled atmospheres: treatment and post-treatment effects of carbon dioxide on pork and beef. Meat Science, California, v. 1, n. 3, p. 195-204, 1977.

SORHEIM, O. et al. Technologycal higienic and toxicological aspects of carbon monoxide used in modified-atmosphere packaging of meat. Trends Food Science Technology, As, Norway, v. 8, n. 9, p. 107-112, 1997.

. The storage life of beef and pork packaged in an atmosphere with low carbon monoxide and high carbon dioxide. Meat Science, As, Norway, v. 52, n. 2, p. 157-164, 1999.

Effect of carbon dioxide on yield, texture and microstructure of cooked ground beef. Meat Science, As, Norway, v. 67, n. 2, p. 231-236, 2004.

SUMAN, S. P. et al. Effect of lactate-enhancement, modified atmosphere packaging, and muscle source on the internal cooked colour of beef steaks. Meat Science, Lexington, v. 81, n. 4, p. 664670, 2009.

TAYLOR, A. A. Packaging fresh meat. In: LAWRIE, R. A. Developments in meat science. London: Elsevier Applied Science, 1985. p. 89-113.

TSIGARIDA, E.; NICHAS, G. J. E. Ecophisyological atributtes of the Lactobacillus sp. and a Pseudomonas sp. on sterile beef filets in relation to storage temperature and film permeability. Journal of Applied of Microbiology, Athens, v. 90, n. 5, p. 696-705, 2001.

VENTURINI, A. C. Embalagens de transporte (masterpack) com atmosfera modificada e absorvedores de oxigênio para aumento da vida útil de carne bovina. 2003. 103 f. Dissertação (Mestrado em Ciência e Tecnologia de Alimentos) - Escola Superior de Agricultura "Luiz de Queiroz", Universidade de São Paulo, Piracicaba, 2003.

Sistemas de embalagens para carne bovina fresca em atmosfera modificada contendo reduzido nível de monóxido de carbono e elevadas concentrações de dióxido de carbono. 2007. 146 f. Tese (Doutorado em Tecnologia de Alimentos) - Universidade Estadual de Campinas, Campinas, 2007.

YOUNG, L. L. et al. Fresh read meat: a place to apply modified atmospheres. Food Technology, Beltsville, v. 42, n. 9, p. 65-76, 1988.

WARREN, K. E. et al. Modified atmosphere packaging of bone in pork loins. Journal of Muscle Foods, Kansas, v. 3, n. 4, p. 283-300, 1992.

WILKINSON, B. H. P. et al. The effect of modified atmosphere packaging with carbon monoxide on the storage quality of master-packaged fresh pork. Meat Science, v. 73, n. 4, p. 605-610, 2006.

ZHAO, Y. et al. Applications of dynamic modified atmosphere packaging systmes for fresh red meat: review. Journal of Muscle Food, Louisiana, v. 5, n. 3, p. 299-328, 1994.

ZAKRYS, P. I. et al. Consumer acceptability and physiochemical characteristcs of modified atmosphere packed beef steaks. Meat Science, Cork, v. 81, n. 4, p. 720-725, 2009.

Recebido: 15/07/2008

Received: $07 / 15 / 2008$

Aprovado: 06/05/2009

Approved: 05/06/2009

Rev. Acad., Ciênc. Agrár. Ambient., Curitiba, v. 7, n. 4, p. 469-482, out./dez. 2009 